\title{
Limitación de la responsabilidad: bases romanas de un dogma iusprivatista ${ }^{*}$
}

\author{
Patricio Lazo González**
}

\begin{abstract}
RESUMEN
En este trabajo el autor pregunta acerca de la posibilidad de considerar a la limitación de responsabilidad un dogma del derecho moderno, en una perspectiva metodológica que privilegia la relación entre dogmática e historia jurídica. A fin de explicitar su pesquisa, se sirve, primero, de algunas explicaciones básicas acerca de la importancia de la identificación de dogmas en el plano de la bistoria jurídica y el derecho comparado. En su análisis, pasa revista a la importancia adquirida durante el siglo XX por la idea de limitación de responsabilidad, primero a partir del surgimiento de las sociedades de responsabilidad limitada y, a continuación, por la introducción de la figura de la empresa individual de responsabilidad limitada. Esta importancia sería un indicio de la aceptación de la limitación de responsabilidad limitada como parte estructural del sistema jurídico. Finalmente, el autor identifica en el mundo romano una primera manifestación del dogma, aunque expresa reservas en torno a la posibilidad, dado el estado de los conocimientos actuales, de poder trazar, sin más, una línea evolutiva.
\end{abstract}

Limitación de responsabilidad - dogmas jurídicos - derecho romano

\section{Limitation of liability: Roman foundations of a private law dogma}

\begin{abstract}
This work discusses the possibility of considering the limitation of liability as a dogma of modern law, in a methodological perspective that privileges the relationship between legal doctrine and legal history. The research, first, draws some basic explanations about the importance of identifying dogmas in terms of legal history and comparative law. In this analysis, it is reviewed the importance acquired by the idea of limitation of liability during the last century, firstly since the emergence of limited liability companies, and later, through the introduction of the figure of the individual companies with limited liability. The pointed out importance would indicate acceptance of limited liability as a structural part of the legal system. Finally, it is identified in the Roman world a first manifestation of this dogma, even though the work expresses reservations about the possibility of drawing an evolutionary line, given the current state of knowledge.
\end{abstract}

$$
\text { Limitation of liability - legal dogmas - Roman law }
$$

* Este trabajo forma parte del proyecto de investigación FONDECYT 1100566. El autor agradece al Fondo Nacional de Ciencia y Tecnología de Chile el apoyo a esta investigación.

** Abogado, Doctor en Derecho, Profesor de Derecho romano en la Facultad de Derecho de la Universidad de Antofagasta, Antofagasta, Chile. patricio.lazo@uantof.cl

Artículo recibido el 19 de diciembre de 2011 y aceptado para su publicación por el Comité Editorial el 31 de mayo de 2012. 


\section{Premisas}

$\mathrm{E}$ ntre las tareas que acometen los historiadores del derecho, una de ellas se refiere a la historia de los dogmas jurídicos, es decir, la que tiene que ver con la identificación y explicación de éstos, así como de sus funciones en un determinado ordenamiento. Esta tarea ha sido desarrollada particularmente en el campo del derecho privado ${ }^{1}$. En la medida en que los productos de estas investigaciones pueden conectarse con otros de similar naturaleza, pero ahora del campo de la dogmática jurídica, sirven también de insumo a las reflexiones sobre el derecho vigente. Se produce de esta forma un diálogo entre perspectivas en principio alejadas, que contribuye a comprender mejor el funcionamiento del sistema jurídico y sus fundamentos.

Es en este contexto en el que me parece de interés propiciar un diálogo metodológico con la dogmática iusmercantilista. Hay varias razones para ello, pero quizá la más importante sea la de enfatizar el componente de historicidad del derecho comercial, a través del análisis de sus dogmas. En efecto, el derecho comercial, a pesar de su permanente reconfiguración -pienso, concretamente, en los esfuerzos en el plano internacional por contar con leyes modelo y uniformes, así como en la insistencia en elaborar principios comunes ${ }^{2}-$, ofrece materias y zonas en las que aún es posible observar la huella de su propia historia. De ahí que estos perfiles tengan un especial interés para el análisis histórico, en especial el histórico-dogmático.

Me parece conveniente al menos esbozar qué puede o debe entenderse por dogma en un sentido jurídico. Se suele asignar este nombre a ciertas construcciones conceptuales presentes en un ordenamiento, traducidas a veces en un amasijo de instituciones o de figuras, cuya permanencia y vigencia no suele ser puesta en cuestión. Desde esta perspectiva, no es raro observar que algunos dogmas jurídicos son identificados también con los fundamentos del sistema. A modo de ejemplo, puede citarse el dogma de los contratos y delitos como fuentes de las obligaciones ${ }^{3}$.

Con todo, me parece que la nota de persistencia del dogma es su característica más llamativa. El dogma resiste el paso de la historia, es decir, de los cambios sociales, políticos y culturales, reapareciendo constantemente, sea en el mismo ordenamiento, sea en otro diferente. En este último caso, deberíamos hablar más propiamente de la "recepción" del dogma. Sea que forme parte de las transformaciones de un mismo

${ }^{1}$ Es lo que caracteriza a las investigaciones histórico-dogmáticas, uno de cuyos mejores ejemplos es la colección Forschungen zur neueren Privatrechtsgeschichte, editada por Böhlau, cuyo primer director fue el historiador del derecho privado, a la vez que iusprivatista, Helmut Coing.

${ }^{2}$ Vid. Illescas Ortiz, R. y Perales Viscasillas, P., Derecho Mercantil Internacional. El Derecho Uniforme, Centro de Estudios Ramón Areces, S.A., Madrid, 2003. Heidemann, M., Methology of Uniform Contract Law. Springer, Berlín, 2007, p. 203 s., hace una positiva valoración de la importancia del argumento histórico en la resolución de problemas propios del Derecho uniforme: "Once more it shows that appropriate answers to modern questions of law cannot be given without recourse to the roots of the present day state and its law. These roots are to be found in legal history and theory".

${ }^{3}$ Sobre lo cual puede verse la obra de Immenhauser, M., Das Dogma von Vertrag und Delikt, Böhlau, Wien/ Köln/Weimar, 2006. 
ordenamiento, sea que se recepcione en otro, la persistencia del dogma se ofrece entonces, a los ojos tanto del legislador como de la ciencia jurídica, como postulado, es decir, como fundamento del sistema, según indicaba antes. En este sentido, se inserta o reinserta en un sistema dado de una forma que podríamos calificar de acrítica. Pero ha de observarse que esta última adjetivación no lleva aparejado un juicio negativo acerca del dogma jurídico, ya que una de las posibles razones por las cuales un dogma se hace presente en un sistema jurídico es porque cumple la función que está llamado a desempeñar dentro de él.

La interpelación a los dogmas, por consiguiente, tiene sentido en cuanto a partir de la identificación de ellos se abren diferentes posibilidades de análisis: de los orígenes, del desarrollo, de las modificaciones, de la configuración actual. Parece, entonces, que si partimos por aceptar la hipótesis de elementos persistentes en la historia del derecho comercial, existirán buenas razones para proponer un estudio histórico-dogmático en el mismo.

\section{FunCIONES DE LA PESQUISA DOGMÁTICO-JURÍDICA}

Puesto que se viene sosteniendo que la identificación de los dogmas jurídicos tiene o puede aspirar a tener una cierta importancia metodológica, me parece conveniente aclarar algunas de las funciones que, en mi opinión, es capaz de cumplir una investigación de estas características.

En primer lugar, creo que puede identificarse una función analítica. Esto, a raíz de que los dogmas, al ser aislados, pueden ser ofrecidos como objeto de diversas perspectivas de estudio, por ejemplo, la histórica o la histórico-comparada, como también las perspectivas teórica y crítica y así varias más. Desde el punto de vista del análisis histórico, la identificación de dogmas jurídicos permite analizar no sólo las transformaciones del sistema, sino también el carácter recursivo de algunas de sus etapas. La referencia a la recursividad del sistema apunta al hecho de conectarse el sistema con sus propias tradiciones, cuestión que se encuentra en el centro del reconocimiento de sí de un sistema jurídico ${ }^{4}$.

En segundo término, creo que también es posible pensar en una función conectada a la comparación jurídica -aquello que solemos llamar derecho comparado-, la que no se suele realizar sobre la base de aspectos específicos y diferenciadores de los sistemas, sino sobre sus rasgos más generales. Éstos pueden ser genéricamente definidos como las

\footnotetext{
${ }^{4} \mathrm{La}$ recursividad del sistema jurídico es un postulado desarrollado por Luhmann, N., El derecho de la sociedad, Herder, México D.F., 2005. D’Orta, M., "Dalla morfogenesi alla struttura del diritto commerciale: imprenditorialità e diritto. L'esperienza di Roma antica”, en Cascione C. y Masi Doria, C. (a cura di), Fides Humanitas Ius. Studi in onore di Luigi Labruna, vol. III, Napoli, Editrice Scientifica, 2007, p. 1593, afirma que "il criterio storico sostiene l'edificio scientifico".
} 
reglas de un determinado sistema y sus relaciones con otro. ${ }^{5}$ Los dogmas allanan esta posibilidad, puesto que se ofrecen al análisis como el tertium comparationis necesario para la actividad comparativa, tal como se exige en la disciplina de la comparación jurídi$\mathrm{ca}^{6} \mathrm{y}$, en este sentido, la historia jurídica - la historia de los dogmas, como se aclarará más adelante- resulta indispensable. En esta línea de pensamiento, James Gordley ha llamado la atención sobre el punto: a su juicio debe desecharse la idea de la mayoría de los comparatistas en orden a realizar la comparación sobre la base de tomar un derecho y compararlo con otros. Tal ejercicio, a juicio de Gordley, se sustenta en una premisa errada: aquella según la cual cada derecho tendría elementos "nacionales", lo que equivale a decir originales y propios. Por el contrario, Gordley postula que mucho del derecho de una nación no es nacional en su origen, sino que está compuesto por lo que se ha dado en llamar "legal formants", que no son sino instituciones, conceptos y reglas que pasan de una nación a otra, pero conservando su contenido ${ }^{7}$.

En tercer lugar, creo que también puede identificarse una función teórica, en el sentido de permitir realizar operaciones tales como aislar conceptos, esquemas, principios o reglas, para, a continuación, ponerlos a disposición de un proceso de progresiva abstracción. Si partiésemos, por proporcionar un ejemplo, como la defensa de los derechos reales, una primera experiencia la ofrecería el derecho romano, a través del instituto de las vindicaciones (en el derecho romano se conocieron tipos diferentes de éstas: reivindicatio, vindicatio usufructus, vindicatio servitutis). Pues bien, en la experiencia jurídica romana no se llega a una figura abstracta y general, como lo sería hablar de la "vindicación”, sino que el proceso de desarrollo concluye con una serie de figuras típicas. Sin embargo, a partir de cierto momento histórico, posterior al de Roma y cuya realidad económico-social era también completamente distinta, comienza la ciencia jurídica un trabajo de progresiva abstracción, de modo de avanzar en pos de una sola noción, la de vindicación, capaz de contener dentro de sí los elementos característicos de todas las vindicaciones posibles. Este proceso se aprecia con nitidez en el Código civil chileno, que expresa este momento de abstracción en su artículo 891 inc. $1^{\circ}$ (inserto en el Título XII De la reivindicación del Libro II del Código), al establecer que "los otros derechos reales pueden reivindicarse como el dominio; excepto el derecho de herencia”. De modo que la rica tipología de vindicaciones romana, en la que cada una de ellas se encuentra en estrecha conexión con las características del ius in re a defender, pierde en la norma civil toda la riqueza de matices que suponía y queda entregada a la interpretación extensiva de normas específicamente aptas para la reivindicación del dominio, con la finalidad de hacerlas aplicables a otros derechos, como el usufructo o la servidumbre.

Es posible, todavía, hacer referencia a una función metodológica. El romanista alemán Christian Baldus ha llamado la atención acerca de lo que él llama la "función

${ }^{5}$ Sobre lo cual, vid. Watson, A., Legal Transplants. An approach to comparative law, University of Georgia Press, Georgia, 1993, p. 6 ss.

${ }^{6}$ Vid. Jansen, N., "Comparative law and comparative knowledge”, en Reimann, M. / Zimmermann, R. (edited by), The Oxford Handbook of Comparative Law, Oxford University Press, Oxford / New York, 2006, pp. $305-338$.

${ }^{7}$ Gordley, J., "Comparative law and legal history”, en Reimann, M. / Zimmermann, R., cit. (n. 6), p. 761 ss. 
purificadora" de la historia del derecho, partiendo de la premisa de entender a ésta como la historia de los dogmas jurídicos. La función purificadora se explica a través del acoplamiento de dos operaciones: la de "descontextualización” y la de "resustancialización":

"Para una perspectiva orientada hacia el presente un fenómeno jurídico sólo es relevante cuando se ha independizado de las circunstancias que le dieron origen (cuestión prioritaria de establecer) y puede insertarse en un contexto moderno (incluso político-jurídico): resustancialización (Resubstantialisierung)" ${ }^{\text {. }}$.

De este modo, parece posible que, a remolque de algunas de las funciones identificadas, se pueda emprender un estudio sobre la limitación de responsabilidad que sirva como base para la discusión y el diálogo entre disciplinas históricas y disciplinas dogmáticas.

\section{3. ¿ES LA RESPONSABILIDAD LIMITADA UN DOGMA?}

La interrogante plantea un problema cuya respuesta no parece sencilla ni evidente. A pesar de la cercanía con uno de los conceptos centrales de esta pregunta (dogma), la subsunción de la responsabilidad limitada en él no puede verificarse sino a través de un proceso lento y en modo alguno inmediato. Con todo, es posible hipotetizar una respuesta afirmativa: es probable que existan fundadas razones para considerar a la limitación de responsabilidad un dogma del derecho privado. Incluso más: es posible sostener que la aparición de este dogma está dotada de una fuerte carga histórica que no limita su existencia a la época moderna -como podría creerse-, sino que resulta verificable ya en época romana. Puesto que es necesario fundar estas afirmaciones a través del examen de ciertos argumentos históricos, creo conveniente centrar la mirada en los siglos XIX y $\mathrm{XX}$, en que el régimen de limitación de la responsabilidad apareció y se desarrolló con fuerza, llegando a convertirse en un elemento central del derecho de sociedades moderno.

En el siglo de las codificaciones, la función de la limitación de la responsabilidad está relacionada con la fortuna e importancia que había adquirido para entonces la sociedad anónima. A este tipo de sociedades les era concedido como privilegio la limitación de responsabilidad, a diferencia de lo que ocurría con el resto de las sociedades -quizá con excepción de alguna variedad de las en comandita-, que admitían como régimen general el de la responsabilidad ilimitada de los $\operatorname{socios}^{9}$, todo lo cual se reflejaría también en la codificación comercial chilena.

El estado de cosas descrito se conservará, al menos en el contexto europeo, hasta que en 1892 haga su aparición en Alemania la sociedad de responsabilidad limitada (Gesellschaft mit beschränkter Haftung, GmbH). La innovación legislativa será, a partir

\footnotetext{
${ }^{8}$ Baldus, C., Regelhafte Vertragsauslegung nach Parteirollen, vol. I. Peter Lang, Frankfurt am Main, 1998, p. 45.

${ }^{9}$ Vid. Meyer, Justus, Haftungsbeschränkung im Recht der Handelsgesellschaften, Springer, Berlín, 2000, p. 199 ss.
} 
de ese momento, recepcionada en el resto del derecho europeo ${ }^{10}$, mientras que, en nuestro país, ya en 1923 tendría lugar la introducción de este régimen de responsabilidad para las sociedades de personas en nuestro derecho comercial, en virtud de la ley 3.918, que permitió el establecimiento de sociedades civiles y comerciales con responsabilidad limitada de los socios.

Todo indica que la innovación en la que consistió la limitación de la responsabilidad de los socios de las sociedades de personas constituyó un acierto, si se toma en cuenta su rápida propagación. En este estado de cosas, era observable con toda claridad un doble régimen de responsabilidad. Por una parte, uno que comenzaba a caracterizar a las sociedades comerciales, en el que la responsabilidad del socio se extendía sólo hasta el monto de su aporte; por otra parte, uno de ilimitación de responsabilidad, que afectaba al comerciante individual y a un número muy menor de sociedades -en el caso chileno, una parte de las sociedades de personas que no se constituían conforme a las reglas de la ley 3.918-. De este modo, se imponía un balance entre dos regímenes de responsabilidad contrapuestos, y cuyo fundamento - la ética de los negocios- quedaba difuminado ante la constitución de personas jurídicas colectivas. Se trataba de una situación que se prestaba precisamente para un cuestionamiento, orientado hacia la progresiva extensión de la limitación de responsabilidad, a favor del empresario individual. Sería en el mundo académico austríaco donde emergerían las ideas que terminarían por inclinar la balanza a favor de la limitación de responsabilidad.

En el primer tercio del siglo XX aparece en escena el trabajo del académico austríaco Oskar Pisko ${ }^{11}$. Este autor ya había provisto a la ciencia iuscomercialista de un interesante estudio, la monografía Das Unternehmen als Gegenstand des Rechtsverkehrs, en 1907. Pero el aporte decisivo vendría en 1910, año de publicación de su artículo sobre la responsabilidad limitada del empresario individual ${ }^{12}$, que tendría un gran impacto legislativo. En efecto, Pisko cerraba su trabajo con una propuesta legislativa, estructurada en torno a nueve secciones, dentro de las cuales se distribuían sesenta y nueve parágrafos. En este estudio, Pisko se hacía eco de la experiencia de la ley de sociedades de responsabilidad limitada. Conforme a ello era posible observar que, en muchos casos, las sociedades eran fundadas en provecho de uno solo de los socios, siendo el otro un mero testaferro. Pisko argumentaba que, al permitir el establecimiento de empresas individuales que pudieran gozar de responsabilidad limitada, no sería necesario recurrir al expediente de crear forzadamente relaciones jurídicas que, en el fondo, eran inexistentes. Con ello se lograría extender el régimen de control de riesgos, pensado para las sociedades, también a los empresarios individuales.

${ }^{10}$ En lo sucesivo incorporarán este régimen de responsabilidad las legislaciones de Portugal (1901), Austria (1906), Francia (1925), Suiza (1937), Italia (1942), Bélgica (1944) y España (1953).

${ }^{11}$ Desde 1909 se desempeñó como Privatdozent de Derecho Comercial y Cambiario de la Universidad de Viena; en 1914 ya era Professor y en 1917 extendió su venia legendi a Derecho civil austríaco.

12 Pisko, O., "Die beschränkte Haftung des Einzelkaufmannes. Eine legislatorische Studie”, en: Zeitschrift für das privat- und offentliche Recht der Gegenwart, vol. 37, 1910, pp. 699-795. El medio académico alemán acostumbra citar esta revista como GrünhtsZ (=Grunhuts Zeitschrift), en honor a su editor, C.S. Grünhut. 
El trabajo de Pisko fue objeto de análisis académico en Suiza y Alemania, pero el mayor impacto se reflejaría en la iniciativa del Principado de Liechtenstein, en el sentido de transformar sus propuestas en norma legal. De este modo, en 1926 y en medio del proceso codificador liechtensteiniano, la regulación sobre Derecho de Personas y Sociedades (Personen und Gesellschaftsrecht, PGR) acogió entre sus artículos 834 a 896, en lo esencial, las propuestas que Pisko había plasmado en su trabajo académico ${ }^{13}$.

La decisión del Principado de Liechtenstein sería decisiva para la aceptación legislativa en diferentes jurisdicciones de las empresas individuales de responsabilidad limitada, que vendrían a resultar el mecanismo de protección y limitación de responsabilidad del que se podrían servir los comerciantes. Con ello, la responsabilidad limitada pasaba a ser, en definitiva, la regla general, quedando el régimen de ilimitación sin mayor posibilidad de aplicación, ante las ventajas ofrecidas por el de limitación, en el contexto del control de riesgos de las empresas modernas. La limitación se había consolidado en poco más de cien años, dejando atrás una larga historia.

Pero si se observa el problema desafectándolo de los aspectos prácticos que la extensión de la limitación de responsabilidad contribuía a resolver, ¿cómo era posible conciliar esta extensión desde el punto de vista de los fundamentos dogmáticos? De entrada, la limitación de responsabilidad había estado desde mucho tiempo al servicio del emprendimiento de grandes empresas y, con ello, a la actuación conjunta de varias personas, los socios; una tal situación podía justificarse desde la perspectiva de facilitar las grandes inversiones, pero la misma justificación no alcanzaba para los pequeños comerciantes o empresarios. Más aún, desde la perspectiva de la ética de los negocios no parecía razonable ni aceptable limitar la responsabilidad de un pequeño comerciante.

Es probable que el éxito de la idea haya estado condicionado, en medida importante, por el desarrollo experimentado por el concepto de patrimonio, concretamente, a partir de la expansión de la noción de "patrimonio separado". Este concepto, ampliamente utilizado en la dogmática moderna, es una construcción de la Pandectística, movimiento bajo el cual se acuñaron las expresiones Zweckvermögen ${ }^{14}$ (patrimonio de afectación) y Sondervermögen (patrimonio especial), que entre sus muchas acepciones sirven para hacer referencia a masas que se adscriben a un mismo titular, como también a aquellos que son sometidos a un régimen específico de administración. Particularmente en relación con la primera de estas acepciones, sería posible hipotetizar algunas relaciones entre su función como garantía de los acreedores del sujeto y la extensión a éste de la limitación de responsabilidad. Desde esta perspectiva, no sería del todo equivocado permitir la limitación de responsabilidad en sujetos determinados (o sea, personas naturales), siempre que el patrimonio al cual se adscribiese tal limitación cumpliese adecuadamente la función de garantía a los acreedores y estuviese dotado de reglas especiales, que

${ }^{13}$ Estas normas y sus modificaciones fueron derogadas el 15 de abril de 1980, en virtud de la Landesgesetzblatt (LGB1.) $1980 \mathrm{Nr} .39$.

${ }^{14}$ Vid. Bekker, E., “Zweckvermögen, insbesondere Peculium, Handelsvermögen und Aktiengesellschaften”, en: Zeitschrift für gesellschaftes Handelsrecht 4, 1861, pp. 499-567. 
supusiesen un adecuado balance entre las expectativas de control de riesgos, por parte del empresario, y las de los acreedores de éste. Así las cosas no puede llamar la atención el hecho de que la limitación de responsabilidad haya pasado a ser un engranaje que ha permitido no sólo la mejor asunción de riesgos, sino la ampliación de las posibilidades del emprendimiento y la consolidación del capital.

La pregunta que al comienzo hacía, acerca de si este estado de cosas permite hablar del dogma de la responsabilidad limitada, creo que puede ser respondida afirmativamente. En una economía capitalista como la moderna, las necesidades de expansión de la misma economía, sus crisis constantes y la consecuente necesidad de controlar los riesgos anejos al emprendimiento, han terminado por derribar las barreras axiológicas que podrían haber justificado en ciertos casos la ilimitación de la responsabilidad. Estas barreras fueron cediendo, en parte ante razones prácticas y en parte ante desarrollos dogmáticos que hicieron posible y atractiva la expansión del régimen de limitación de responsabilidad más allá de los supuestos aceptados hace un siglo. Bajo estas circunstancias, la responsabilidad limitada se ofrece como un dogma, una construcción cuya existencia deja de ser paulatinamente objeto de revisión y crítica y que se ofrece como una constante de los sistemas jurídicos modernos.

\section{LA LIMITACIÓN DE LA RESPONSABILIDAD EN LA EXPERIENCIA JURÍDICA ROMANA}

Expresaba antes mi convencimiento de que el moderno fenómeno de la limitación de responsabilidad no corresponde a una experiencia exclusiva del derecho moderno, sino que es posible encontrar una manifestación del mismo en la experiencia jurídica romana. Creo que es necesario aclarar que la afirmación recién hecha tiene un valor descriptivo limitado, con lo que quiero decir que no puede, en caso alguno, servir para derivar conclusiones acerca de una hipotizable línea de continuidad histórica. Es decir, afirmar que el dogma encuentra una manifestación concreta en la experiencia romana no confiere validez a una conclusión en el sentido de sostener que la experiencia moderna es una heredera directa de la romana. Una afirmación de esta naturaleza debiese ser el producto de un estudio sobre el tratamiento del tema en los juristas medievales y posteriores, cuestión acerca de la cual este trabajo no indaga. Dicho de otra manera: si me refiero a la experiencia jurídica romana, ello tiene que ver con mi interés por referirme a otra experiencia histórica -distinta socioeconómicamente a la moderna-, con miras a un ejercicio de comparación histórico-jurídica que puede ofrecer resultados de interés.

El análisis del desarrollo del dogma de la responsabilidad limitada en el mundo romano exige, previamente, tomar distancia ante ciertos prejuicios, bien o mal fundados en la historiografía del siglo XIX, acerca de la economía del mundo romano y de la acumulación de riquezas en el mismo. La visión de la sociedad y economía romanas, en cuanto dependientes de la agricultura y del saqueo de los pueblos y territorios conquistados, ha venido siendo desvirtuada desde hace tiempo por estudios sobre su 
economía ${ }^{15}$. Hoy es ampliamente aceptado que, a raíz de la expansión de la economía romana a partir de los siglos III-II a.C. y hasta el s. II d.C., se dio paso a una intensa actividad de intercambio, que incidió en la conformación de una clase social no sólo poderosa económicamente, sino influyente desde el punto de vista político. Esta confluencia de factores no podía menos que impactar en el desarrollo del derecho, lo que se tradujo en algunas innovaciones, dentro del derecho honorario.

A lo anterior sería necesario agregar todavía un apunte metodológico. En efecto, la romanística del siglo XX, particularmente a partir de la segunda mitad, fue modificando algunas de sus perspectivas de análisis, para centrarse en materias específicamente económicas, que eran tradicionalmente estudiadas como parte de las instituciones del derecho de familia, separándolas de este marco y resistematizándolas. En este sentido, adquirieron notoriedad las acciones adyecticias, en especial aquellas en las que era posible identificar algunos elementos propios del emprendimiento económico romano -caracterizado por la existencia de la esclavitud-, en particular aquellos supuestos de actividad económica realizada a través de dependientes. En este sentido, una importante constatación la debemos a Andrea di Porto, cuyo análisis sirvió para centrar la mirada en aquellos ciudadanos romanos que realizaban sus actividades económicas no valiéndose del contrato de sociedad, sino a través de la utilización de esclavos. Los ciudadanos romanos podían, en efecto, emprender varias actividades económicas valiéndose de los esclavos como mecanismo de fraccionamiento del riesgo de ellas ${ }^{16}$.

En el contexto de las premisas señaladas, adquiere sentido la aparición de la demanda por mecanismos adaptables a las necesidades del comercio; uno de estos mecanismos lo constituye la limitación de responsabilidad contractual. En efecto, la expansión del territorio, la utilización de rutas marítimas y el contacto con diversos comerciantes suponen no sólo oportunidades para el comercio, sino también amenazas. El control de riesgos, por consiguiente, se vuelve exigencia. Ante este estado de cosas, el pretor, a través de su ius edicendi (función normativa), recoge estas necesidades del entorno, traduciéndolas en mecanismos protección, que en alguna medida expresan un balance entre las expectativas de los comerciantes (limitación de responsabilidad) y los acreedores (efectividad del cumplimiento coactivo de la obligación). La limitación de responsabilidad comienza así un camino que la lleva hacia su estabilización y desarrollo, a través del trabajo de discusión y puesta en práctica de sus categorías y mecanismos. Todos ellos son operados por la jurisprudencia romana, a través de su actividad asesora, lo que equivale decir la relacionada con la celebración de negocios jurídicos (cavere) como también con los asuntos

${ }^{15}$ Un estudio que, a pesar de su lejanía conserva aún valor como punto de referencia, es el del historiador estadounidense Frank, T., An economic survey on ancient Rome, vols. 1-5., The Johns Hopkins Press, Baltimore, 1933-1940. Más recientes, en cambio, son los estudios de von Freyberg, H.-U., Kapitalverkehr und Handel im römischen Kaiserreich (27 v. Chr.-235 n. Chr.), Albert-Ludwigs-Universität Freiburg i. Br., Freiburg, 1989; Aubert, J.-J., Business managers in ancient Rome, E. J. Brill, Leiden, 1994; Drexhage, H.-J. / Konen, H. / Ruffing, K., Die Wirtschaft des Römischen Reiches (1.-3-Jabrbundert), Akademie Verlag, Berlín, 2002; Lazo, P., "Emprendimiento en Roma antigua: de la política al Derecho”, en Revista de Derecho (P. Universidad Católica de Valparaíso), 33 , segundo semestre 2009, pp. 641-670.

${ }^{16}$ Di Porto, A., Impresa collettiva e schiavo "manager" in Roma antica. Giuffrè, Milano, 1984. 
procesales (agere). Pero sin lugar a dudas no es sino en el repositorio de esas reflexiones y descripciones, esto es, la literatura jurídica romana, donde quedan reflejados esos desarrollos. Con todo, la emergencia de la estructura dogmática es posible observarla a través de lo que puede llamarse "estructuras concomitantes", o sea, un conjunto de mecanismos y engranajes cuyo funcionamiento operacionaliza y hace posible los efectos que está llamado a producir el dogma de la limitación de responsabilidad de modo tal de integrarlo eficiente a la estructura general del sistema jurídico.

\section{ESTRUCTURAS CONCOMITANTES AL DOGMA DE LA LIMITACIÓN DE RESPONSABILIDAD EN EL DERECHO ROMANO}

En lo que sigue, me limitaré a enunciar lo que, en mi opinión, son las estructuras concomitantes más relevantes desde el punto de vista que me he propuesto analizar, y cuyo estudio puede prestar alguna utilidad al interesado en descripciones de historia comparada.

\subsection{Patrimonios especiales ${ }^{17}$}

El peculio de los dependientes, hijos o esclavos, es un patrimonio especial. La idea romana de que el paterfamilias (quien desempeña el rol de empresario, en cuanto vértice de la actividad económica de la que se viene hablando) podía constituir patrimonios para quienes eran sus dependientes -y lo eran en razón de carecer de capacidad jurídica, no de obrar- impidió hasta cierto punto que en el mundo romano pudiera concebirse una noción de patrimonio cercana a la que el derecho europeo-continental conoció, esto es, aquella que sistematiza al patrimonio entre los atributos de la personalidad, de modo tal que corolario necesario del mismo es que a cada persona no podría corresponderle más que uno. En este sentido, para la comprensión del funcionamiento del patrimonio en la experiencia jurídica romana es necesario hacer algunas precisiones, que paso a describir sumariamente.

La primera es que, en el mundo romano, la titularidad del patrimonio y su correspondiente gestión (lo que incluye la facultad de disposición del mismo) pueden no estar radicadas en la misma persona. Más concretamente, en la materia que nos ocupa el patrimonio pertenece al paterfamilias, pero puede ser gestionado por un dependiente, el que puede ser un hijo de familia o un esclavo. Ambos tienen en común el hecho de que carecen de capacidad jurídica, lo que no representa un obstáculo para que los actos de disposición realizados sobre el patrimonio sean válidos. Desde una perspectiva procesal, ello implica que, ante la eventualidad de un conflicto en sede procesal, la acción que un tercero quiera ejercitar, a causa de los negocios celebrados con el dependiente, no se

${ }^{17}$ Sobre esta materia puede consultarse la interesante monografía de Andrés Santos, F., Subrogación real y patrimonios especiales en el derecho romano clásico. Secretariado de Publicaciones e Intercambio Científico de la Universidad de Valladolid, Valladolid, 1997. 
dirige contra éste, sino contra su paterfamilias o dueño, que es aquel que se menciona en la condemnatio y que, por tanto, en caso de decisión adversa, es quien resulta obligado a pagar la condena.

La segunda precisión tiene que ver con la eventual relación de comunicabilidad/ incomunicabilidad entre los patrimonios. Como se ha sugerido, un empresario romano podía constituir tantos patrimonios especiales como dependientes y recursos que para ello dispusiera; en este sentido, no existían limitaciones. Todavía más, se admite la posibilidad de que un solo dependiente pueda estar a cargo de más de un peculio. La pregunta, por consiguiente, se relaciona con los efectos que pueden darse entre esta variedad de peculios, en aquello que se mienta como su comunicabilidad entre éstos. Lo que puede plantearse en términos de si, ante supuestos de insolvencia de uno de los patrimonios, los demás se pueden ver afectados, o bien permanecen inmunes tales problemas.

El análisis de la comunicación entre peculios depende de si ella es analizada desde un punto de vista horizontal, o bien desde uno vertical. Prima facie, puede decirse que la comunicación entre peculios opera verticalmente, pero no horizontalmente.

Desde el punto de vista del análisis de la comunicabilidad horizontal, los dispositivos de responsabilidad contractual que afectan a cada uno de los peculios operan de forma diferenciada y aislada, de modo tal que las deudas de un peculio no son realizables en otro peculio. Esta afirmación es válida para dos supuestos, en los cuales el titular es el mismo empresario (o paterfamilias): el primero, que los peculios hayan sido radicados en diferentes dependientes, para actividades económicas diferenciadas. El segundo supuesto es que los peculios se encuentren radicados en el mismo dependiente, es decir, consiste en la posibilidad de que el empresario encomiende al dependiente el ejercicio de diferentes actividades económicas, dotándolo para cada una de ellas de un patrimonio diferente. Un ejemplo extraído de las fuentes romanas contribuirá a aclarar este punto: en el Digesto, en un pasaje proveniente de la obra de Ulpiano, a propósito de la acción tributoria (especialmente vinculada a supuestos de insolvencia de patrimonios especiales) encontramos la siguiente decisión:

D. 14.4.5.15. Si el esclavo tenía varios acreedores, pero algunos relativos a determinadas mercancías del peculio, ¿se habrán de confundir todos sin distinción de mercancías y habrán de ser llamados todos al reparto? Si uno tenía dos negocios distintos, por ejemplo, uno de trajes y otro de tejidos y tenía un acreedor en cada uno de ellos, creo que deben ser llamados al reparto separadamente, porque cada uno debe ser considerado más como acreedor de la mercancía del peculio que del propio esclavo $^{18}$.

La expresión "mercancía del peculio" (merx peculiaris) hace referencia a un patrimonio especial, que es constituido para la realización de determinadas negociaciones. Ciertas

${ }^{18}$ Utilizo, tanto para ésta como para las demás citas del Digesto, la traducción de d’Ors, A. et al., El Digesto de Justiniano, Aranzadi, Pamplona, 1968-1976. 
acciones, como la actio tributoria, guardaban una estrecha relación con la mercancía del peculio, por cuanto, en caso de insolvencia de la misma, se procedía a un reparto (tributio) de los bienes que componían ese patrimonio. Como puede apreciarse, el texto de Ulpiano no deja lugar a dudas en cuanto a que un esclavo puede tener más de un peculio y que las acreencias (los acreedores, en el texto) se relacionan directamente con la masa patrimonial más que con la persona que gestiona el patrimonio. Se trata de un ejemplo del grado de despersonalización que hubo alcanzado en el derecho romano, hacia fines de la época clásica, la obligación ${ }^{19}$.

A su turno, la comunicación vertical es un poco más compleja: puede darse el supuesto de que un esclavo que ha sido dotado de un peculio (esclavo principal o servus ordinarius) y que en el contexto de la gestión de este patrimonio especial adquiera para sí un esclavo (servus vicarius), el que queda también dotado de un peculio. Éste depende económicamente del peculio del esclavo principal, en cuanto es creación suya. En este caso, la insolvencia del peculio del servus ordinarius supone la insolvencia del peculio del vicarius. Sin embargo, la comunicabilidad no opera en el sentido inverso, por lo que la insolvencia del peculio del vicarius no supone la del esclavo principal. Respecto de la comunicabilidad entre el patrimonio del empresario y el de sus esclavos (principal y vicarius) rigen idénticas reglas:

D. 14.4.5.1. Si un esclavo dependiente (vicarius) de mi esclavo (ordinarius) negociara, y lo hiciera con mi conocimiento, me obligaré por la acción tributoria; si lo ignorara yo, pero lo supiese el esclavo principal, escribe Pomponio, en el libro 60 de Comentarios al Edicto, que se ha de dar acción respecto del peculio de este esclavo y que no se debe deducir del peculio del dependiente lo que se debe al principal, aunque sí se deduce lo que me debe a mí. Pero si tanto el principal como yo hubiésemos sabido, dice Pomponio que procede tanto la acción tributoria como la de peculio: la tributoria en nombre del esclavo dependiente, la de peculio en el del principal. El demandante debe elegir la acción con la que prefiere demandar, pero de modo que entre en la distribución, tanto lo que se me debe a mí como lo que se debe al esclavo principal, siendo así que, si el principal hubiese ignorado la negociación, se deduciría íntegro lo que le debía el esclavo dependiente.

En este caso, es un poco más complejo de observar la situación, puesto que el pasaje se centra en la acciones a ejercitar (tributoria y de peculio), pero en ellas se observa el esquema dominus-ordinarius / ordinarius-vicarius y la forma en que afectan verticalmente los problemas originados en el peculio del servus vicarius. Pueden distinguirse tres supuestos, todos los cuales centran la mirada en los efectos de la gestión de su patrimonio por parte del vicarius. Los supuestos se diferencian entre sí según si el dueño de los esclavos

${ }^{19}$ Vid. Serrao, F., Impresa e responsabilità a Roma nell'età commerciale, Pacini editore, Pisa, 1989, p. 29 ss.; Di Porto, A., Impresa collettiva, cit. (n. 16) p. 309 ss.; Cerami, P., "Negotiationes e negotiatores", en Cerami, P. / Di Porto A. / Petrucci, A., Diritto comerciale romano, 2a ed., Giappichelli, Torino, 2004, p. 60. 
o el ordinarius tienen conocimiento de los negocios celebrados por el vicarius. De este modo, cuando ha existido tal conocimiento, procede la acción tributoria; caso contrario, la de peculio. Lo central, de cara al argumento aquí defendido, es que cualquiera sea la acción que se ejercita -se llega incluso a decir que es el demandante el que debe elegir la acción a ejercitar- las consecuencias de los actos del vicarius no producen efectos en los demás patrimonios y las acciones ejercitables sólo inciden en la posibilidad que tendrían el dueño o el esclavo principal de cobrar sus créditos en el patrimonio del vicarius con preferencia a los demás acreedores -cuestión a la que se hace referencia con la noción de "deducción", empleada en el pasaje citado.

\subsection{Limitación e ilimitación de responsabilidad asociada a la existencia de un patrimonio especial}

Como hubo ocasión de analizar en el punto anterior, las deudas ocasionadas por la gestión de un patrimonio especial, por parte de un dependiente, están limitadas a los bienes existentes en dicho patrimonio. Las acciones de peculio y tributoria de las que se habló antes son las que se encargan de operacionalizar la limitación de responsabilidad. De ahí que los acreedores del dependiente sólo puedan tener como expectativa del cobro de sus créditos el hecho de realizar los bienes del peculio a través de diferentes mecanismos de reparto.

Ante este estado de cosas, surge la pregunta acerca de si es posible modificar los mecanismos de limitación de responsabilidad, volviendo a ésta ilimitada ${ }^{20}$.

Una situación como la descrita exigía de parte del mundo romano una respuesta. Atento a los requerimientos del entorno, el pretor dispuso la existencia de un mecanismo de ilimitación de la responsabilidad, es decir, de superación de la barrera demarcada por el peculio: la autorización vinculante o iussum. Se trata de un mecanismo que opera de forma muy sencilla: sin importar si el dependiente actúa o no gestionando un peculio, lo relevante es que el dueño de este esclavo puede declarar que los negocios celebrados por éste cuentan con su autorización, todo lo cual ha de ser conocido por la contraparte. La puesta en práctica de este sencillo mecanismo permite a su cocontratante -transformado en acreedor- hacer cobro en el patrimonio del dominus autorizante las deudas contraídas por el dependiente, sin límite alguno. De esta manera, el iussum se ofrece como un mecanismo que se inserta en un cuadro de negociaciones que exigen condiciones diferentes a las normales y que resultan beneficiosas para el empresario que desea contratar, aunque sea poniendo en riesgo su propio patrimonio ${ }^{21}$.

${ }^{20}$ Piénsese, por ejemplo, en la existencia de un comerciante que cuente con una gran capacidad de negociación. Llegado el caso, no es descartable que éste, al establecer los extremos de la negociación, no se muestre conforme con las posibilidades ofrecidas por el patrimonio del dependiente y pretenda que sus créditos no se cobren en este peculio, sino en el patrimonio del empresario que tiene por contraparte.

${ }^{21} \mathrm{Vid}$. Esta situación, que se encuentra registrada en documentos negociales de época romana, se analiza en Lazo, P., "Contribución al estudio de la actio quod iussu”, en Revista de Estudios Histórico-Jurídicos, 32, 2010, p. 99 ss. Sobre el iussum puede consultarse Wacke, A., "Fideiussio = iussum? Bürgschaften für 


\subsection{Par condicio creditorum}

El conocido principio del igual tratamiento de los acreedores tiene ciertamente un origen romano. Su aparición está vinculada al funcionamiento de los patrimonios especiales y algo de ello ha sido adelantado en los puntos anteriores.

Para explicarlo mejor, es necesario partir de la idea de autonomía patrimonial, tal como ella se desarrolla en el mundo romano. Como hemos tenido ocasión de ver, una vez creado un peculio a favor de un esclavo, este patrimonio, aunque jurídicamente pertenece al empresario, alcanza un grado de autonomía tal que puede admitir incluso la celebración de negocios jurídicos entre el dependiente y el propio empresario (es decir, entre el esclavo y su dueño). Se trata de una situación que no puede calificarse de autocontratación, puesto que, como ya hemos visto, para la jurisprudencia clásica, se es “acreedor más de la mercancía (= patrimonio especial) que del esclavo”. Este hecho trae aparejada a favor del empresario que contrata con su propio dependiente la constitución de un privilegio que opone a los demás acreedores al momento de la realización del peculio: el privilegium deductionis, es decir, la posibilidad de practicar una deducción de sus créditos contra el peculio del esclavo sus créditos antes que los demás acreedores. Estos últimos podrán concurrir con posterioridad, pero verán limitadas sus posibilidades de cobro a aquellos bienes que no hayan ido a pagar las acreencias del dominus.

Desde luego, la situación descrita, que corresponde al ejercicio de la actio de peculio, deja a los acreedores en una posición que bien puede resultar perjudicial, al verse expuestos a que nada quede en el patrimonio del dependiente. Y es probable que teniendo precisamente esto en cuenta, el pretor haya optado por introducir una nueva acción, similar a la de peculio, pero que mejora la situación del conjunto de acreedores, de cara al privilegio del que disfruta el dominus: la actio tributoria. El ejercicio de esta acción está sujeto a un supuesto: que los negocios emprendidos por el dependiente fueran conocidos por el empresario. Basta la prueba de este solo hecho para que el dominus pierda de inmediato su privilegium deductionis y concurra con los demás acreedores en igualdad de condiciones ${ }^{22}$.

Como puede apreciarse, el principio de la par condicio creditorum está estrechamente asociado, desde el punto de vista dogmático, a la pérdida de un privilegio, su valor es descriptivo antes que prescriptivo. No prescribe que los acreedores deban ser tratados en igualdad de condiciones, sino que describe la efectiva situación de igualdad que produce la actio tributoria, en cuanto el único acreedor que contaba con un privilegio deja ahora de tenerlo y participa del reparto de los bienes en pie de igualdad con los

den eigenen Gewaltunterworfenen oder Gewalthaber, en Index. Quaderni Camerti di Studi Romanistici, 27, 1999, pp. 523-549.

${ }^{22} \mathrm{La}$ introducción de esta acción mereció el elogio de Ulpiano (D. 14.4.1 pr.): "No es pequeña tampoco la utilidad de este edicto, en virtud del cual el dueño, que de otro modo tiene una posición privilegiada en los contratos de su esclavo (porque cuando se obliga solamente por el peculio, se hace la estimación de éste, deducido lo que el esclavo debe al dueño), sea llamado, sin embargo, a contribución por este edicto como un acreedor cualquiera, siempre que hubiera sabido que el esclavo negociaba con mercancía del peculio". 
demás acreedores ${ }^{23}$. Esta pérdida del privilegio opera, entonces, como un mecanismo de resguardo para los terceros contratantes ${ }^{24}$.

\subsection{Separación patrimonial y grupos de empresa}

La diversificación de los patrimonios en varios dependientes del mismo empresario permite imaginar la existencia en el mundo romano de realidades en parte equivalentes a nuestros modernos holdings. En efecto, la separación patrimonial, como se ha indicado, impide el contagio de la insolvencia entre los distintos patrimonios, salvo en el supuesto antes indicado de un contagio vertical hacia abajo. Ello permite, al mismo tiempo, que al vender a uno de los esclavos gestores junto con su patrimonio, el empresario no hiciera más que transferir una unidad económica (empresa) a otro, sin más formalidades que la propia de la transmisión del esclavo y de los inmuebles que el peculio pudiera tener. ${ }^{25}$

\subsection{Enriquecimiento sin causa}

Hay buenas razones para estimar que el problema del enriquecimiento sin causa encuentra un buen contexto para su explicación ante el supuesto de la limitación de responsabilidad. En efecto, puede advertirse que en el plano de la ilimitación de responsabilidad, al no existir diferenciación de patrimonios, el problema del enriquecimiento no se origina, ya que siempre es el patrimonio del dueño el que responde ante las acreencias, sea que se haya empobrecido, sea que se haya enriquecido. En otras palabras, puesto que la separación patrimonial puede llegar a operar en desmedro del interés de los acreedores por ver satisfechos sus créditos, es que aparecen mecanismos que, bajo ciertos supuestos, facultan a la restitución de ciertas sumas, las que se hacen valer en el patrimonio del empresario, ahí donde sea comprobable que la gestión del dependiente operó en provecho de éste. En tales casos, los acreedores disponen de la actio de in rem verso, mediante la cual pueden perseguir en el patrimonio del empresario el monto en el que éste se enriqueció a causa de la gestión del patrimonio especial.

Puede citarse, a modo de ejemplo, el caso que aparece en las fuentes romanas, extraído de la obra de Ulpiano:

D. 15.3.3.5. El propio Labeón dice que si un esclavo hubiera prestado a otros las monedas que yo le presté, puede ser su dueño demandado por la acción de provecho

${ }^{23}$ Vid. Lazo, P., "El contexto dogmático de la par condicio creditorum en el derecho romano", en Revista de Derecho (Universidad Católica del Norte) vol. 17 No 2, 2010, pp. 79-97.

${ }^{24}$ Petrucci, A., Per una storia della protezione dei contraenti con gli imprenditori, Giappichelli, Torino, 2007, p. 80.

${ }^{25}$ Serrao, F., cit. (n. 19) p. 29 ss. destaca las múltiples formas en que podían organizarse los grupos de empresa, así como sus mecanismos de transmisión; Di Porto, "Servus e libertus. Strumenti dell'imprenditore romano”, en Cerami, P. / Di Porto, A. / Petrucci, A., cit. (n. 19) p. 89, a propósito de la venta del esclavo negociante, afirma que ello "concreta un originale fenomeno di trasferimento di impresa. E se nel peculio vi sono peculia di altritanti servi vicarii-negotiatores, allora la vedita, in blocco, del peculio dell'ordinarius é vendita del grupo di imprese, inclusi i negotiatores. Per cuo può ben dirsi che lo strumento-schiavo consente la circolazione di impresa". 
obtenido, porque fue él quien adquirió el crédito; cuya opinión aprueba Pomponio, siempre que el esclavo no adquiera el crédito como propio del peculio, sino como de la administración del dueño. Por lo cual el dueño queda obligado solamente a ceder a su acreedor las acciones y a hacerle procurador si es que no estima le convenga tener el crédito contra tal deudor ${ }^{26}$.

Se trata de un caso que hay que ubicar dentro del ejercicio de la empresa bancaria, ${ }^{27}$ que contiene el supuesto de que un tercero que presta una cantidad de dinero a un esclavo y éste hace lo propio entregando, a su turno, las monedas a otro. La jurisprudencia romana ofrece, para el mismo caso, dos variantes de una misma solución: i) Labeón concede la acción de in rem verso sin más; ii) Pomponio, en cambio, sólo la concede si el esclavo no adquiere el crédito como propio del peculio, sino como propio del dueño. Esta última solución presupone, a su turno, una estricta separación de peculios. Destaco en esta parte que la solución sigue en los términos de la responsabilidad limitada: según Pomponio, ante el ejercicio de la acción in rem verso, el dueño sólo estaría obligado a ceder la acción que tuviese contra el tercero, o a hacerle procurador, no a más.

\section{CONCLUSIONES}

El diálogo entre las disciplinas históricas y las dogmáticas está siempre por hacer y requiere de la atención tanto de los historiadores como de los estudiosos del derecho positivo. Por lo demás, hay razones para creer que un debate pueda resultar instructivo, de cara a los análisis a partir de los cuales emprender el estudio del derecho moderno. Cuanto he querido poner de manifiesto en este trabajo dice relación con la posibilidad de enriquecer el análisis dogmático a partir del esclarecimiento de un material de naturaleza histórica y dogmática de contornos precisos.

Queda por ver cuánto más allá sea posible extender el análisis y la valoración que los estudiosos del derecho vigente estarán dispuestos a darle. Pero no me parece inútil ofrecer una perspectiva de análisis que proponga una conjunción de elementos y que se proponga algo más que el comentario de normas legales. Es probable que, desde la perspectiva de la práctica del derecho, no sea posible ver con facilidad la conveniencia de avanzar en un estudio de esta naturaleza. En este sentido, nunca está de más postular que los desafíos de la ciencia jurídica, aunque vinculados a la aplicación del derecho, en parte importante son propios e independientes y quizá esta sola constatación constituya un aliciente importante para no abandonar su desarrollo.

${ }^{26}$ Sobre el pasaje, vid. Buti, I., Studi sulla capacità patrimoniale dei "servi". Jovene, Napoli, 1976, p. 73 ss.

${ }^{27}$ Sobre lo cual, vid. Petrucci, A., Mensam exercere. Studi sull'impresa finanziaria romana. Napoli, Jovene, 1991. 


\section{BiBLIOGRAFÍA}

Andrés Santos, F., Subrogación real y patrimonios especiales en el derecho romano clásico. Secretariado de Publicaciones e Intercambio Científico de la Universidad de Valladolid, Valladolid, 1997. Aubert, J.-J., Business managers in ancient Rome, E.J. Brill, Leiden, 1994.

Baldus, C., Regelhafte Vertragsauslegung nach Parteirollen, vol. I. Peter Lang, Frankfurt am Main, 1998.

BekKer, E., “Zweckvermögen, insbesondere Peculium, Handelsvermögen und Aktiengesellschaften”, en: Zeitschrift für gesellschaftes Handelsrecht 4, 1861, pp. 499-567.

Buti, I., Studi sulla capacità patrimoniale dei "servi". Jovene, Napoli, 1976.

Cerami, P., "Negotiatones e negotiatores", en Cerami, P. / Di Porto A. / Petrucci, A., Diritto comerciale romano, $2^{a}$ ed., Giappichelli, Torino, 2004, pp. 34-63.

Di Porto, A., Impresa collettiva e schiavo "manager" in Roma antica. Giuffrè, Milano, 1984.

Di Porto, A., "Servus e libertus. Strumenti dell'imprenditore romano", en Cerami, P. / Di Porto, A. / Petrucci, A., Diritto comerciale romano, $2^{\mathrm{a}}$ ed., Giappichelli, Torino, 2004.

D'OrTA, M., "Dalla morfogenesi alla struttura del diritto commerciale: imprenditorialità e diritto. L'esperienza di Roma antica", en Cascione C. y Masi Doria, C. (a cura di), Fides Humanitas Ius. Studi in onore di Luigi Labruna, vol. III, Napoli, Editrice Scientifica, 2007, pp. 1593-1616

Drexhage, H.-J. / Konen, H. / Ruffing, K., Die Wirtschaft des Römischen Reiches (1.-3Jabrhundert), Akademie Verlag, Berlín, 2002.

Frank, T., An economic survey on ancient Rome, vols. 1-5., The Johns Hopkins Press, Baltimore, 1933-1940.

Gordley, J., "Comparative law and legal history”, en Reimann, M. / Zimmermann, R. (edited by), The Oxford Handbook of Comparative Law, Oxford University Press, Oxford / New York, 2006, pp. 753-773.

Heidemann, M., Methology of Uniform Contract Law. Springer, Berlín, 2007.

Illescas Ortiz, R. y Perales Viscasillas, P., Derecho Mercantil Internacional. El Derecho Uniforme, Centro de Estudios Ramón Areces, S.A., Madrid, 2003.

Immenhauser, M., Das Dogma von Vertrag und Delikt, Böhlau, Wien/Köln/Weimar, 2006.

JAnsen, N., "Comparative law and comparative knowledge”, en Reimann, M. / Zimmermann, R. (edited by), The Oxford Handbook of Comparative Law, Oxford University Press, Oxford / New York, 2006, pp. 305-338.

Lazo, P., "Emprendimiento en Roma antigua: de la política al Derecho", en Revista de Derecho (P. Universidad Católica de Valparaíso), 33, segundo semestre 2009, pp. 641-670.

Lazo, P., "El contexto dogmático de la par condicio creditorum en el derecho romano", en Revista de Derecho (Universidad Católica del Norte) vol. 17 No 2, 2010, pp. 79-97.

Lazo, P., "Contribución al estudio de la actio quod iussu", en Revista de Estudios Histórico-Jurídicos, 32, 2010, pp. 83-105.

Luhmann, N., El derecho de la sociedad, Herder, México D.F., 2005.

MeYer, Justus, Haftungsbeschränkung im Recht der Handelsgesellschaften, Springer, Berlín, 2000.

Petrucci, A., Mensam exercere. Studi sull'impresa finanziaria romana. Napoli, Jovene, 1991.

Petrucci, A., Per una storia della protezione dei contraenti con gli imprenditori, Giappichelli, Torino, 2007.

Pisko, O., "Die beschränkte Haftung des Einzelkaufmannes. Eine legislatorische Studie”, en: Zeitschrift für das privat- und offentliche Recht der Gegenwart, vol. 37, 1910, pp. 699-795.

SERraO, F., Impresa e responsabilità a Roma nell'età commerciale, Pacini Editore, Pisa, 1989.

Von Freyberg, H.-U., Kapitalverkehr und Handel im römischen Kaiserreich (27 v. Chr.- 235 n. Chr.), Albert-Ludwigs-Universität Freiburg i. Br., Freiburg, 1989. 
Watson, A., Legal Transplants. An approach to comparative Law, University of Georgia Press, Georgia, 1993.

WACKE, A., "Fideiussio = iussum? Bürgschaften für den eigenen Gewaltunterworfenen oder Gewalthaber, en Index. Quaderni Camerti di Studi Romanistici, 27, 1999, pp. 523-549. 